\title{
Characterization of Recombinant p20 Trypsin Inhibitor, a New Protein from Glycine max
}

\author{
Akihito MATSUSHIMA, Yoshiyuki ASHIDA, Junko WATANABE, Toshifumi HIRATA* \\ Department of Mathematical and Life Science, Graduate School of Science, \\ Hiroshima University, 1-3-1 Kagamiyama, Higashi-Hiroshima 739-8526, Japan \\ *Corresponding author E-mail address: thirata@sci.hiroshima-u.ac.jp
}

Received 12 September 2002; accepted 15 Octover 2002

\begin{abstract}
A 20 - kDa protein ( 220$)$ having $40 \%$ sequence similarity with Kunitz-type soybean trypsin inhibitor (STI) from Glycine max (soybean) cultured cells was expressed in Escherichia coli. The recombinant p20 (rp20) inhibited the activity of trypsin at the same level as STI (rp20, Ki $=50 \mathrm{nM}$; STI, Ki $=75$ $\mathrm{nM}$ ), and both rp20 and STI displayed non-competitive inhibition of trypsin activity. Although STI inhibited the activity of $\alpha$-chymotrypsin $(K \mathrm{i}=140 \mathrm{nM})$ and elastase $(K \mathrm{i}=207 \mathrm{nM})$, rp20 did not inhibit the activity of $\alpha$-chymotrypsin and elastase. These results show that p20 is a novel type of trypsin inhibitor.
\end{abstract}

Key words: $\quad \alpha$-Chymotrypsin, Elastase, Glycine $\max$ (soybean), Inhibition mechanism, Kunitz-type trypsin inhibitor.

\section{Abbreviations}

BAPA, benzoyl-L-arginine $\mathrm{p}-$ nitroanilide; STI, soybean trypsin inhibitor.

Recently we isolated from Glycine $\max$ (soybean) cultured cells, a 20 - kDa protein (p20) having trypsin inhibitory activity on the basis of its GTP binding activity (Hirata et al, 1999). The cDNA clone (accession number AB029441) of p20 was isolated and sequenced, and the putative amino acid sequence of p20 indicated an approximately $40 \%$ sequence similarity with Kunitz-type soybean trypsin inhibitor (STI) (Ashida et al., 2000). Protease inhibitors belonging to the STI family has been extensively studied and at least 10 members are reported in soybean cells (Kim et al., 1985; Jofuku et al., 1989). The amino acid residues at reactive site of trypsin inhibitors were reported to be Arg (63)-Ile (64) in $\mathrm{Ti}^{\mathrm{a}}$, $\mathrm{Ti}^{\mathrm{b}}$ and $\mathrm{Ti}^{\mathrm{c}}$ (Blow et al., 1974; Sweet et al., 1974) and His (63)-Ala (64) in KTi1 and KTi2 (Jofuku et al,, 1989). However, the corresponding amino acid residues of $\mathrm{p} 20$ were Lys (63)--Ile (64) (Ashida et al., 2000). These facts suggested that $\mathrm{p} 20$ is a novel type of trypsin inhibitor. In order to clarify the inhibitory properties of $\mathrm{p} 20$, the recombinant $\mathrm{p} 20$ ( $\mathrm{rp} 20$ ) was expressed and then its inhibitor activity and mechanism were investigated.

Total cellular RNA was isolated from soybean cultured cells using an ISOGEN kit (Nippon Gene Co.). RNA purification was then followed by single -stranded cDNA synthesis using an oligo $(\mathrm{dT})_{20}$ M13M4 adopter primer. Two oligonucleotides, HVR - $1 \quad(+136$ to $+154 ;$ accession number AB029441) and HVF-1 $(+674$ to +693$)$, were used as primers for polymerase chain reaction (PCR) amplification to produce the matured form $\mathrm{p} 20$ cDNA from single-stranded cDNA. These primers have Bam HI and XhoI restriction sequences, respectively. The amplification was done at $94^{\circ} \mathrm{C}$ for 2 min for denaturation, $55^{\circ} \mathrm{C}$ for $30 \mathrm{~s}$ for annealing, and $70^{\circ} \mathrm{C}$ for $30 \mathrm{~s}$ for synthesis, followed by 29 cycles of these conditions. The final PCR product of 571 base pairs in length was obtained, and ligated to the pPCR-Script SK(-) vector (Stratagene) followed by transformation into Escherichia coli DH5 $\alpha$ competent cells. Double-stranded DNA sequencing by the dideoxynucleotide chain termination method was done using a BigDye terminator cycle sequencing kit (Applied Biosystems) and an $\mathrm{ABI}$ PRISM310 genetic analyzer (Applied Biosystems). Then, the cDNA clone of p20 was digested with BamHI (New England Biolabs) and XhoI (New England Biolabs), and ligated to the pGEX-6P-1 expression vector (Amersham Bioscience), which 
contains a region coding for expression as a fusion protein with glutathione $S$-transferase (GST), to construct pGEX - 6P-1(p20). Finally, the pGEX-6P 1 (p20) was transformed into $E$. coli BL21 competent cells. The full-length sequence of $p 20$ cDNA cloned into pGEX-6P-1(p20) was confirmed by DNA sequencing.

The $E$. coli strain transformed with pGEX- $6 \mathrm{P}-$ 1(p20) was cultivated at $30^{\circ} \mathrm{C}$ for $6 \mathrm{~h}$ in LB medium (Luria et al., 1960) containing $50 \mu \mathrm{g} \mathrm{ml}^{-1}$ of ampicillin. After the incubation, isopropyl- $\beta-\mathrm{D}$-thiogalactopyranoside was added to a final concentration of $0.1 \mathrm{mM}$ in the cultures and incubated at $16^{\circ} \mathrm{C}$ for $16 \mathrm{~h}$. After centrifugation, the $E$. coli pellet was resuspended in sonication buffer (1 $\mathrm{mM}$ EDTA, $50 \mathrm{mM}$ Tris- $\mathrm{HCl}(\mathrm{pH} 8.0), 0.5 \mathrm{mM}$ dithiothreitol and $51 \mathrm{mM} \mathrm{NaCl}$ ) and sonicated. The sonicated mixture was centrifuged to obtain the soluble protein fraction. The GST fusion protein was purified using glutathione Sepharose 4B (Pharmacia Biotech) affinity column chromatography and digested by PreScission protease (Amersham Biosciences) to release $\mathrm{rp} 20$ from the GST fusion protein (Fig. 1). The purified rp20 was finally dialyzed to exchange buffers to $10 \mathrm{mM}$ Tris- $\mathrm{HCl}(\mathrm{pH} \mathrm{7.0)}$ containing $0.5 \mathrm{mM}$ dithiothreitol. The amino acid sequence at the $\mathrm{N}$-terminal region of $\mathrm{rp} 20$ was analyzed using an Applied Biosystems model 373A protein sequencer. The analysis of amino acid sequence at the $\mathrm{N}$-terminal region of $\mathrm{rp} 20$ (GPLGSDIVFDTEGNPIR) showed that $\mathrm{rp} 20$ has a $\mathrm{N}$-terminal amino acid sequence of p20 (DIVFD-

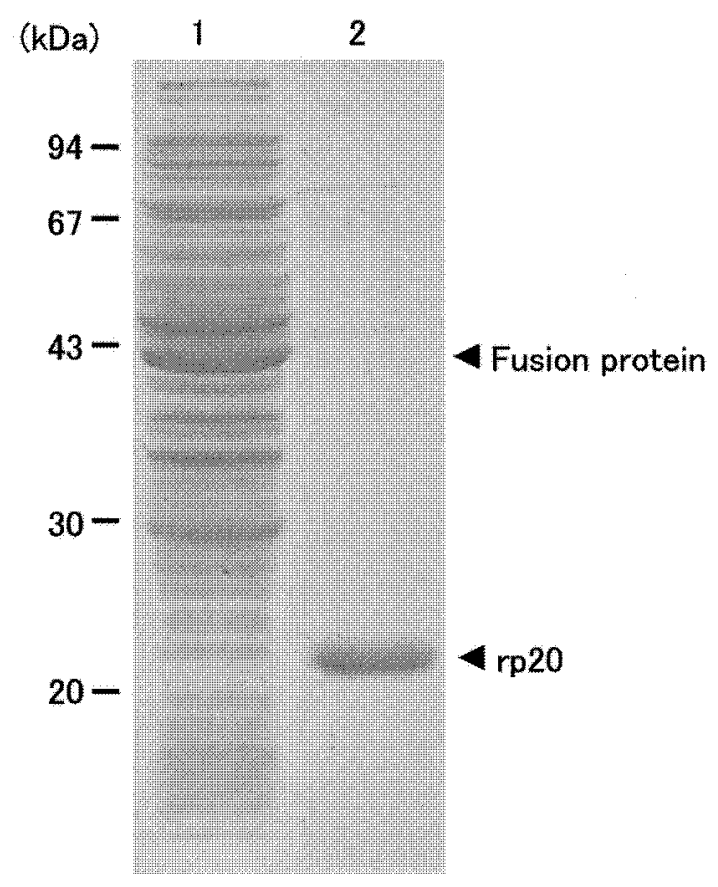

Fig. 1 Expression and purification of $\mathrm{rp} 20$. Lane 1, crude soluble fraction; lane 2, purified rp20.
TEGNPIR) and a sequence from part of the multiple cloning site of pGEX $-6 \mathrm{P}-1$ vector (GPLGS). The observed molecular mass of rp20 $(20,495 \pm 20)$ by TOF-MASS spectrum was in agreement with a theoretical molecular weight $(20,506)$ of $\mathrm{rp} 20$ with the additional peptide (GPLGS). These results confirmed that $\mathrm{rp} 20$ has the same amino acid sequence as that deduced from the putative amino acid sequence of the p $20 \mathrm{cDNA}$ clone.

The amino acid residues at the reactive site of Ti $\left(\mathrm{Ti}^{\mathrm{a}}, \mathrm{Ti}^{\mathrm{b}}\right.$ and $\left.\mathrm{Ti}^{\mathrm{c}}\right)$, which were most intensively studied STI, are Arg (63)-Ile (64) (Blow et al., 1974; Sweet et al., 1974). However, $\operatorname{Arg}(63)$ of $\mathrm{Ti}$ is replaced by Lys(63) in p20 (Ashida et al., 2000). It has also been reported that enzymatic replacement of the Arg (63) of Ti with Lys conserved the trypsin inhibitor activity of Ti (Sealock et al., 1969). Therefore, the trypsin inhibition activities of $\mathrm{rp} 20$ and STI were compared. The inhibition activity for the hydrolysis of benzoyl-L-arginine $p$-nitroanilide (BAPA) was measured by the change in absorbance at $410 \mathrm{~nm}$. For double-reciprocal analysis, rp20 $(37 \mathrm{nM})$ or STI $(47 \mathrm{nM})$ was preincubated at $25^{\circ} \mathrm{C}$ in a total volume of $1.5 \mathrm{ml}$ of $100 \mathrm{mM}$ Tris-$\mathrm{HCl}(\mathrm{pH} 7.0$ ) containing $90 \mathrm{nM}$ trypsin. After $8 \mathrm{~min}$ incubation, 0.5-2.4 mM BAPA (Peptide Institute, Inc) was added, and the absorbance at $410 \mathrm{~nm}$ was continuously measured for $15 \mathrm{~min}$ using a UV/VIS Spectrophotometer. For the stoichiometric examination of trypsin inhibition of $\mathrm{rp} 20$ and STI, the increasing amount of rp20 or STI was preincubated at $30^{\circ} \mathrm{C}$ in a total volume of $0.3 \mathrm{ml}$ of $100 \mathrm{mM}$ Tris$\mathrm{HCl}(\mathrm{pH} \mathrm{7.0)}$ containing $83 \mathrm{nM}$ trypsin. After $4 \mathrm{~min}$ incubation, $333 \mu \mathrm{M}$ BAPA was added, and the absorbance at $410 \mathrm{~nm}$ was continuously measured for $6 \mathrm{~min}$ by a microplate reader. One unit of trypsin activity was defined as the change of $p$-nitroaniline concentration per second $\left(\mathrm{nM} \mathrm{s}^{-1}\right)$. Fig. 2 shows the

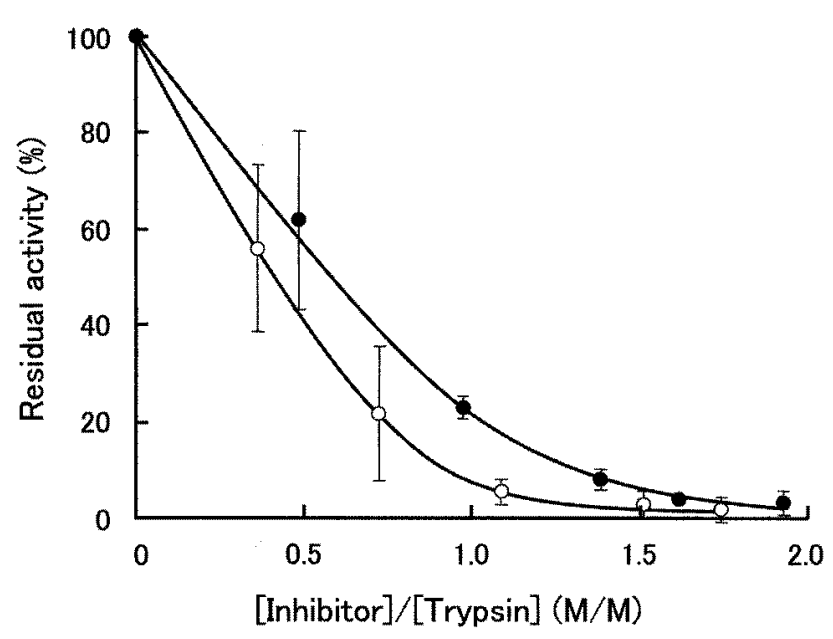

Fig. 2 Inhibitory activity of rp20 and STI. Open circle, STI; closed circle, rp20. 
Table 1. Comparison of the inhibitory activities of $\operatorname{rp} 20$ and STI

\begin{tabular}{llcrr}
\hline \multirow{2}{*}{ Protease } & Substrate & $\mathrm{pH}$ & \multicolumn{2}{c}{ Ki value (nM) } \\
\cline { 5 - 5 } & & & rp20 & \multicolumn{1}{c}{ STI } \\
\hline Trypsin & $\mathrm{Bz}-\mathrm{Arg}-p \mathrm{NA}$ & 7.0 & 50 & 75 \\
$\alpha$-Chymotrypsin & Suc-Ala-Ala-Pro-Phe-MCA & 7.0 & $\mathrm{Ni}$ & 140 \\
Elastase & Suc-Ala-Ala-Ala-pNA & 7.0 & $\mathrm{Ni}$ & 207 \\
\hline
\end{tabular}

"Ni denotes no inhibition.

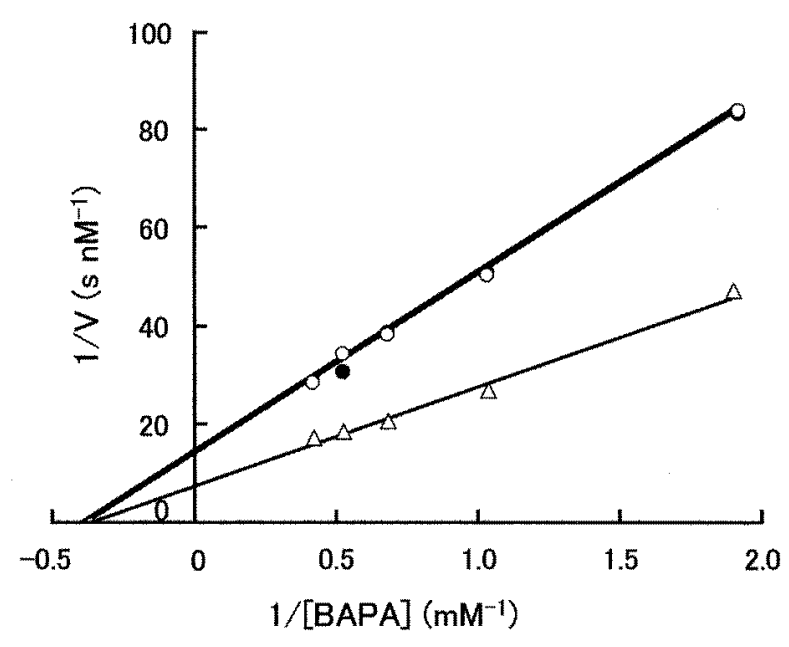

Fig. 3 Double-reciprocal plot of the initial rate of trypsin activity toward BAPA in the presene and absence of inhibitors. Open triangle, no inhibitor; closed circle, rp20; open circle, STI.

stoichiometry of trypsin inhibition with $\mathrm{rp} 20$ and STI. Both rp20 and STI inhibited trypsin at a ratio of $1: 1$. The double-reciprocal plot analysis for the activity of trypsin with $\mathrm{rp} 20$ and STI showed that trypsin activity was non-competitively inhibited by both rp20 and STI (Fig. 3). The $K \mathrm{i}$ values of rp20 and STI $(50 \mathrm{nM}$ and $75 \mathrm{nM})$ were analogous, as shown in Table 1. These results show that both $\mathrm{rp} 20$ and STI interact with trypsin and trypsin-BAPA complex and inhibit trypsin activity by similar mechanisms.

It has been reported that STI can inhibit $\alpha$ chymotrypsin activity (Kunitz, 1947) and that the active site of STI toward trypsin and $\alpha$-chymotrypsin is analogous (Bidlingmeyer et al., 1972). Therefore, the inhibition activities of rp20 and STI toward $\alpha$-chymotrypsin and elastase were measured to clarify their specificity toward other serine protease. The chymotrypsin activity was measured by the fluorimetric determination (excitation, 360 $\mathrm{nm}$; emission, $465 \mathrm{~nm}$ ) of the generation of 7 amino-4-methylcoumarin (AMC) in 96 well micro - titer plates. The rp20 (214 nM) or STI ( $48 \mathrm{nM})$ was preincubated at $30^{\circ} \mathrm{C}$ in a total volume of $0.2 \mathrm{ml}$ of $100 \mathrm{mM}$ Tris $-\mathrm{HCl}(\mathrm{pH} 7.0)$ containing $10 \mathrm{nM} \alpha-$ chymotrypsin (Wako Pure Chemicals Ind., Ltd).
After 4 min incubation, $2 \mu l$ of $1.5-10 \mathrm{mM}$ succinyl - L-alanyl- $\mathrm{L}$-alanyl- $\mathrm{L}$-proly $-\mathbf{L}$-phenylalanine 4-methylcoumaryl-7-amide (Peptide Institute, Inc) was added and the changes in relative fluorescence units were continuously measured for $6 \mathrm{~min}$. The elastase activity was measured by the hydrolysis of succinyl-L-alanyl-L-alanyl-L-alanine $p$ - nitroanilide (suc-Ala-Ala-Ala-pNA) (Peptide Institute, Inc) by a similar procedure to that described for the trypsin inhibitor activity, except for the concentration of elastase (Wako Pure Chemicals Ind., Ltd) (22 nM), rp20 (260 nM), STI (195 nM) and suc-Ala-Ala-Ala-pNA (0.24-1.308 mM). $\alpha$ Chymotrypsin was non-competitively inhibited by STI $(K \mathrm{i}=140 \mathrm{nM})$, but not by rp20 (Table 1 ). Elastase was also inhibited by STI $(K \mathrm{i}=207 \mathrm{nM})$, but not by rp20 (Table 1). An excessive amount of rp20 did not inhibit either serine protease. These results show that $\mathrm{rp} 20$ has different specificity toward serine proteases than STI.

The $\mathrm{X}$-ray crystallographic analysis of a $\mathrm{Ti}$-trypsin complex has indicated that Ti interacts with the trypsin at the positions of Asp (1), Asn (13), Ser (61), Tyr (62), Arg (63), Ile (64), Arg (65) and His (71) of $\mathrm{Ti}$ (Sweet et al., 1974). However, the corresponding amino acid residues of p20 (Ashida et al., 2000) were different from those of Ti at the positions of Phe (62), Lys (63), Leu (65) and Leu (71). Such differences in the amino acid residues at the positions of inhibitor-trypsin interaction may cause distinct specificity to serine proteases. On the other hand, Jofuku et al. (1989) reported another type of trypsin inhibitor, KTi (KTi1 and KTi2), whose corresponding amino acid residues are His (63)-Ala (64). They have reported that the KTi genes do not encode proteins with trypsin inhibitor activity, because KTi from transformed tobacco plants with KTi genes did not react with a Kunitztype trypsin inhibitor antibody (Jofuku et al., 1989). These results suggest that the STI family should be classified into three subfamilies and p20 may be a new member of the STI family. 


\section{Acknowledgement}

We thank Dr. Shunsuke Izumi of Hiroshima University for his useful discussion and the measurement of TOF-MASS spectrum.

\section{References}

Ashida, Y., Matsushima, A., Tsuru, Y., Hirota, T., Hirata, T., 2000. Isolation and sequencing of a cDNA clone encoding a $20-\mathrm{kDa}$ protein with trypsin inhibitory activity. Biosci. Biotechnol. Biochem., 64: 1305- 1309.

Bidlingmeyer, U. D. V., Leary, T. R., Laskowski, M. Jr., 1972. Identity of the tryptic and $\alpha$-chymotryptic reactive sites on soybean trypsin inhibitor (Kunitz). Biochemistry, 11: 3303-3310.

Blow, D. M., Janin, J., Sweet, R. M., 1974. Mode of action of soybean trypsin inhibitor (Kunitz) as a model for specific protein-protein interactions. Nature, 249: 5457

Hirata, T., Izumi, S., Tsuji, S., 1999. A 20-kDa protein with the GTP-binding and trypsin inhibitory activities from Glycine max. Biosci. Biotechnol. Biochem., 63: 18161818.
Jofuku, K. D., Goldberg, R. B., 1989. Kunitz trypsin inhibitor genes are differentially expressed during the soybean life cycle and in transformed tobacco plants. Plant Cell, 1: 1079-1093.

Kim, S. H., Hara, S., Hase, S., Ikenaka, T., Toda, H., Kitamura, K., Kaizuma, N., 1985. Comparative study on amino acid sequences of Kunitz-type soybean trypsin inhibitors, $\mathrm{Ti}^{\mathrm{a}}, \mathrm{Ti}^{\mathrm{b}}$, and $\mathrm{Ti}^{\mathrm{c}}$. J. Biochem. (Tokyo), 98: 435-448.

Kunitz, M, 1947. Crystalline soybean trypsin inhibitor: II. general properties. J. Gen. Physiol., 30: 291-310.

Luria, S. E., Adam, J. N., Teng, R. C., 1960. Transduction of lactose utilizing ability among strains of Escherichia coli and Shigella dysenteriae and the properties of the transducing phage particles. Virology, 12: $348-390$.

Sealock, R. W., Laskowski, M. Jr., 1969. Enzymatic replacement of the arginyl by a lysyl residue in the reactive site of soybean trypsin inhibitor. Biochemistry, 8: 37033710 .

Sweet, R. M., Wright, H. T., Janin, J., Chothia, C. H., Blow, D. M., 1974. Crystal structure of the complex of porcine trypsin with soybean trypsin inhibitor (Kunitz) at $2.6-\AA$ resolution. Biochemistry, 13: $4212-4228$. 